\title{
Papercrete Bricks - An Alternative Sustainable Building Material
}

\author{
Myriam Marie Delcasse*, Rahul $\mathrm{V}^{* *}$, Abhilash $\mathrm{C}^{* * *}$, Pavan $\mathrm{M} \mathrm{K}^{* * * * *}$, \\ Gangadhar***** \\ *Assistant Professor, Dept. of Civil Engineering, Maharaja Institute of Technology Mysore, Mandya-38, \\ Email: myriammd_ce@mitmysore.in \\ **Dept. of Civil Engineering, Maharaja Institute of Technology Mysore, Mandya-38 \\ *** Dept. of Civil Engineering, Maharaja Institute of Technology Mysore, Mandya-38 \\ **** Dept. of Civil Engineering, Maharaja Institute of Technology Mysore, Mandya-38 \\ ***** Dept. of Civil Engineering, Maharaja Institute of Technology Mysore, Mandya-38
}

\begin{abstract}
A large amount of non-renewable resources is consumed by the construction industry throughout the world. Everyday tons of waste papers are discarded as landfill or dump sites than those recycled. It is learnt that it takes about fifteen trees to make a ton of paper which means that 720 million trees are used once and then buried as landfills each year. In order to address these issues it has become imperative to push the boundaries of research in the field of innovative sustainable construction materials. This study is one such kind of efforts. Papercrete is a new composite material comprising of waste papers and cement. In this investigation, an attempt is made to produce an alternative material using waste papers. This could help eradicate a few of the environmental hazards caused by the construction industry. But there is no proper code for the mix proportioning of papercrete bricks. Therefore, a mix proportion of [Cement: Paper: Sand] 1:1.25:2 was chosen on trial and error basis. All the necessary engineering properties are studied and compared with the conventional bricks and discussions on its potential uses are made.
\end{abstract}

Keywords - Papercrete, Paper Sludge, Lightweight, Structure, Strength

\section{INTRODUCTION}

Since the last decade, there is a large demand on building material industry owing to the increasing population which is causing a chronic shortage of building materials [4,5]. This has become a major challenge to civil engineers to produce and use alternate materials. The constant developmental activities in civil engineering and growing industrial activities have created a continuous demand for building materials which satisfy all the stringent requirements regarding the short-term and long-term performance of the structure. As the structures of tomorrow become taller and more complex, the materials of construction will be required to meet more demanding standards of performance than those in force today (Fuller 2006). India's present housing shortage is estimated to be as high as 31 million according to census and out of these shortages 24 million units are in rural areas and 7 million units in urban areas. Such a large housing construction activities require a huge amount of money. Out of this total cost of housing construction, building materials contribute to about $70 \%$ of cost in developing countries like India. The increase in the popularity of using environmental friendly, low-cost and light weight construction materials in building industry has brought about the need to investigate how this can be achieved by benefiting the environment as well as maintaining the material [2].

This experimental study investigates the potential use of waste paper for producing a low-cost and light weight composite brick as a building material. These alternative bricks were made with papercrete. Papercrete will offer a way to turn "trash" paper into inexpensive houses that are quite strong, well-insulated and easily built. There is no specific codal provision for the mix design of papercrete as it is still in its developing stage.

In the present scenario, the whole world is facing a major problem of environmental pollution by the waste industrial materials like as they are dumped as landfills. Fly ash, micro silica, steel slag etc., are a few examples of the waste materials. Hence these materials can be used as alternatives in the construction industry which will help meeting the sustainable development requirements.

\section{RESEARCH OBJECTIVES}

A set of papercrete mixes were prepared with cement, wastepaper sludge, river sand and manufactured sand.

The major objective of this research program is replacing the costly and scarce conventional building bricks by an innovative and alternative building bricks which satisfies the following characteristics:

$>$ Lightweight

$>$ Less water absorption 
Inflammable

$>$ Abundant availability

$>$ Environmental friendly

$>$ Cost Effective

\section{Materials Used}

\section{RESEARCH DETAILS}

To attain these goals, materials were collected from various sources.

\subsection{Paper}

In this study, paper is the main constituent material. Different types of Papers are like newspapers, record sheets, old newspapers, magazines. Paper is nothing but wood cellulose, which is considered as a fibrous material. Cellulose is the second most abundant material on earth after rock. Cellulose is a natural polymer with a long chain of linked sugar molecules i.e., $\beta$-D-glucose. The cellulose chain bristles with polar - $\mathrm{OH}$ groups. These groups form many hydrogen bonds with -OH groups on adjacent chains, bundling the chains together. The hydrogen bonding forms the basis and strength [4]. The typical cellulose structure is shown in Fig.1.

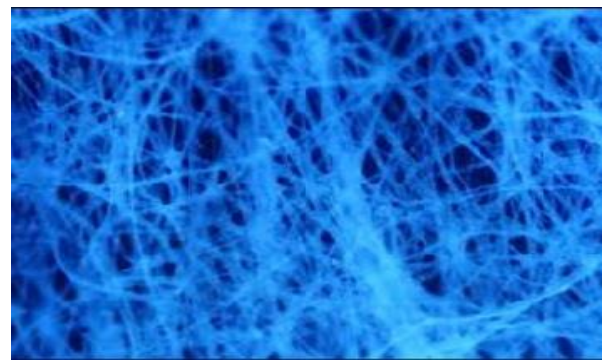

Fig.1 Microscopic view of Cellulose

\subsection{Cement}

Cement used in this study was 53 grade Ordinary Portland Cement (OPC) conforming to IS: $\mathbf{8 1 1 2}$ - 1989 cement used.

\subsection{Fine Aggregates}

Fine aggregates used was River Sand and Manufactured Sand (M-Sand) passing $4.75 \mathrm{~mm} \mathrm{IS}$ sieve as per the specifications in IS: 383 - 1970 were used.

\section{Experimental Procedure}

There is no specific procedure for casting the bricks and the procedure followed in this investigation was as per our conveniences. The mix proportion adopted was 1:1.25:2 [Cement: Paper sludge: River Sand \& M-Sand]. River sand was used as M-sand has the tendency to absorb more water.
Of the total ratio of sand content, $60 \%$ was M-Sand. The bricks were cast in this ratio and the tests on the bricks were then conducted after 14 and 21 days.

\subsection{Preparation of Paper Sludge}

The papers used were from a variety of sources. Newspapers, record sheets, magazines, etc., These papers were torn into small pieces and soaked in water for 3-4 days until they started degrading to paste like form. Then the papers were removed from water and ground in a mixer to obtain the paper sludge. The pulp is later taken on non-absorbent plate after having the extra water squeezed out. This pulp generating procedure consumed a lot of time and was tedious. But for mass production, mechanically operated tow mixers can be recommended to reduce the cost [4].
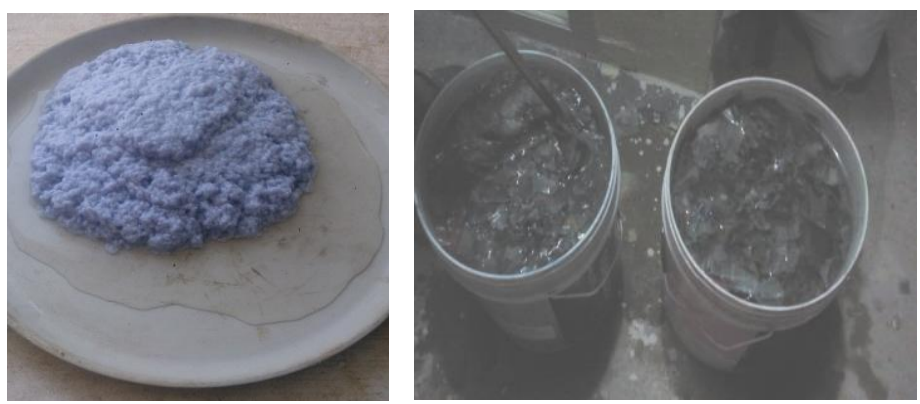

Fig.2 Soaked papers and Paper sludge

\subsection{Mixing of dry ingredients}

The other constituents of papercrete - cement, river sand and M-sand, were dry mixed until a uniform colour was formed. In this work, mixing was manually done and the paper sludge thus obtained was then mixed with it to get the desired papercrete mix. No additional water was added unless it was essential. 


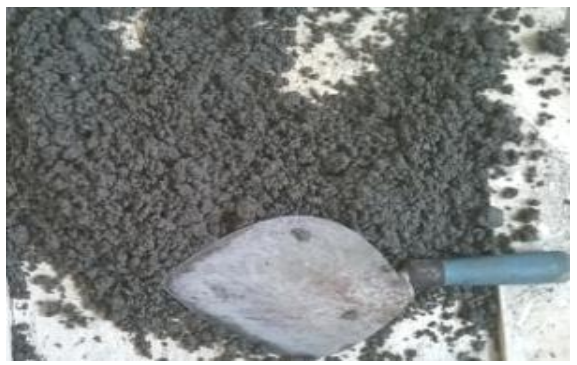

Fig.3 Papercrete Mix

\subsection{Mould Specifications}

Brick mould made of ply wood sheets was used. The sheet is extended to outside for holding the mould while preparation of brick. The dimensions of the mould were that of the modular bricks i.e., $190 \mathrm{~mm}$ x $90 \mathrm{~mm}$ x $90 \mathrm{~mm}$.

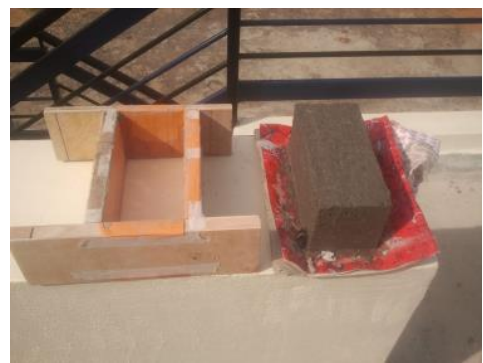

Fig.4 Papercrete mould and brick

\subsection{Casting of bricks}

The mix should be poured in the mould within 30 minutes of mixing on a table and the material was compacted using a tamping rod manually. The extra mix was removed by a metal strike. Two moulds were used at a time to cast the bricks at a faster rate. A few bricks were then sun- dried for 21 days and a few others were sun-dried for 7 days and later cured in water for the next 14 days.

\section{Tests and Results}

Various tests were conducted to analyse the properties of the papercrete bricks and compared with that of the conventional bricks.

\subsection{Weight}

Table.1 Weight of Papercrete Bricks

\begin{tabular}{|c|c|c|}
\hline $\begin{array}{c}\text { Sl. } \\
\text { No. }\end{array}$ & $\begin{array}{c}\text { Type of Papercrete } \\
\text { Bricks }\end{array}$ & Weight (kg) \\
\hline 1 & Sun-dried & 1.538 \\
\hline 2 & Water-cured & 1.702 \\
\hline
\end{tabular}

The results shows that the maximum weight of the papercrete bricks are less than $2 \mathrm{~kg}$ in both cases. This is almost half the weight of the conventional bricks which is 3 to $3.5 \mathrm{~kg}$. Sun-dried bricks weighed lesser than water-cured bricks.

\subsection{Compressive Strength Test}

The test was carried out by a Compression Testing Machine. This test was carried out on the $7^{\text {th }}$, $14^{\text {th }}$ and $21^{\text {st }}$ day from the date of casting. It was observed while testing the specimens that the bricks did not crush or completely collapse, it just compressed like squeezing a rubber. So the load was applied to half compression.

The test results are shown below.

Table.2 Compressive Strength, MPa

\begin{tabular}{|c|c|c|c|}
\hline Type of & \multicolumn{3}{|c|}{ Compressive Strength } \\
\cline { 2 - 4 } Papercrete Bricks & $\mathbf{7}$ days & $\mathbf{1 4}$ days & 21 days \\
\hline Sun-dried & \multirow{2}{*}{1.025} & 1.25 & 1.65 \\
\cline { 3 - 4 } Water-cured & & 1.10 & 1.40 \\
\hline
\end{tabular}




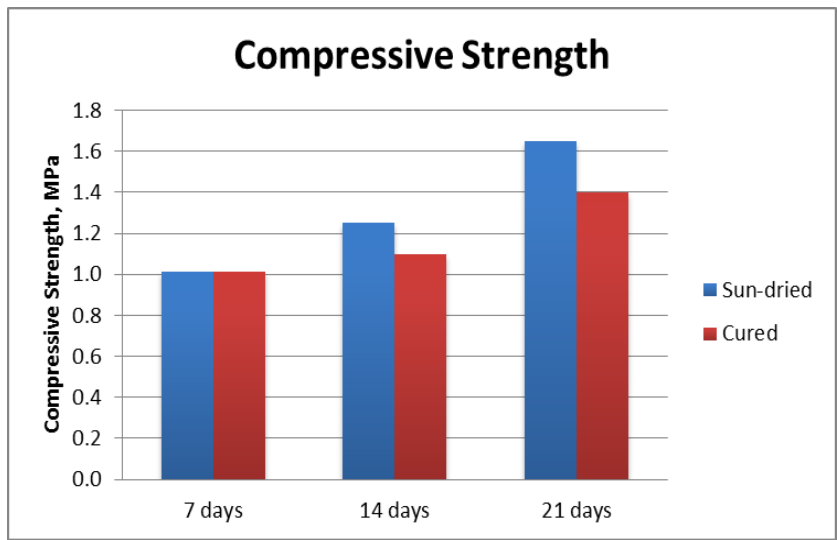

Fig.5 Compressive Strength of Papercrete Bricks

From the above test results, the compressive strength of Papercrete bricks which were sun-dried showed an increase in strength while the water-cured bricks strength decreased with the no. of curing days. It can also be inferred that these bricks have elastic behaviour and are less brittle.

\subsection{Water Absorption Test}

The procedure for water absorption test for bricks was conducted as per IS: 3495 - Part 2. A brick is taken and weighed dry. It was then immersed in water for a period of 24 hours. It was weighed again and the difference in weight indicates the amount of water absorbed by the brick. It should not, in any case, exceed $20 \%$ of weight of dry brick. Water absorption value of bricks largely influences the bond between brick and mortar. If water absorption in bricks is more and bricks are not soaked before the masonry work, the water from freshly laid mortar is likely to be absorbed by bricks. This results into poor mortar strength as the sufficient quantity of water will not be available for hydration process.

The test results for water absorption are illustrated below.

Table.3 Water Absorption of Papercrete Bricks

\begin{tabular}{|c|c|c|}
\hline Sl. No. & $\begin{array}{c}\text { Type of Papercrete } \\
\text { Bricks }\end{array}$ & $\begin{array}{c}\text { Water } \\
\text { Absorption (\%) }\end{array}$ \\
\hline 1 & Sun-dried & 24.565 \\
\hline 2 & Water-cured & 20.025 \\
\hline
\end{tabular}

From the above table, it can be concluded that the papercrete bricks come under III Class (sundried bricks) and I Class (water-cured bricks). The bricks which were sun-dried absorbed more water than the other. So these bricks are not suitable for water logging and exterior walls.

\subsection{Efflorescence Test}

This test was conducted to know the presence of any alkaline matter in papercrete bricks. The brick samples were taken and placed along their ends in a dish. The depth of immersion in water was $2.5 \mathrm{~cm}$. The whole arrangement is placed in a warm, well-ventilated room until the water evaporates in the dish. When the water is completely absorbed and the brick appears to be dry, the same procedure is repeated. The bricks are later examined for efflorescence after second evaporation. If the white deposit covers about $10 \%$ surface, the efflorescence is said to be slight and it is considered as moderate, when the white deposit cover about $50 \%$ surface. If grey or white deposits are found on more than $50 \%$ of surface, the efflorescence becomes heavy and it is treated as serious.

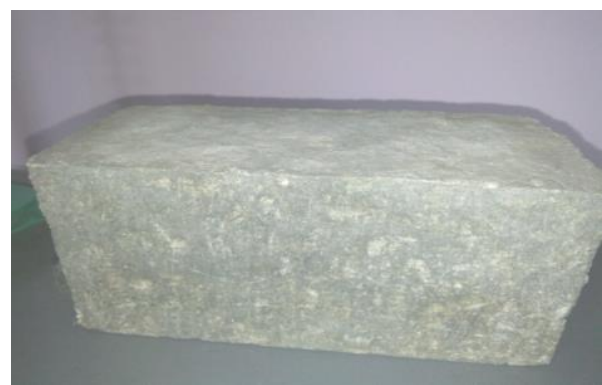

Fig.6 Specimen after Efflorescence Test 
It was observed from these tests that there were no perceptible deposits in both the type of bricks i.e., the bricks are free from soluble salts or any alkaline matter.

\subsection{Fire Resistance Test}

A brick which is used for construction should not be flammable in open flame, so this test was carried out for these bricks. The following are the steps involved in this test,

- First, the brick was wiped with cloths and all the foreign matters were removed.

- Then the flammable sticks were fired. After that, the bricks were held on the flame for 30 minutes.

- The bricks were then observed.
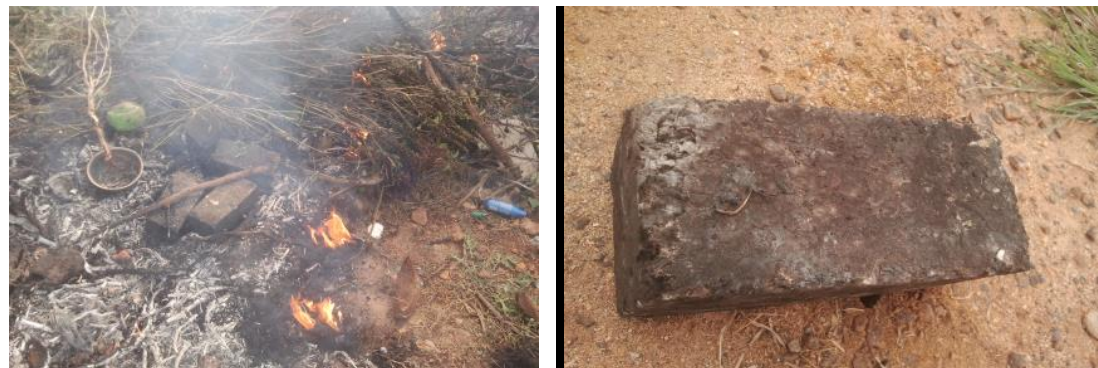

Fig.7 Fire Resistance Test

From the above test, it was observed that the papercrete bricks just smouldered like charcoal. But if these bricks are exposed to fire for several hours, they will become ashes. Interior plaster and exterior stucco should be provided on these bricks, to prevent them from getting burnt.

\subsection{Structure}

In this test, the bricks were broken and the structures of that bricks were examined, whether they were free from any defects such as holes, lumps, etc., The fibrous concrete brick were cut into equal parts and observed. The structure of the papercrete brick was homogenous, compact, and free from defects and this brick pieces look like a sponge.

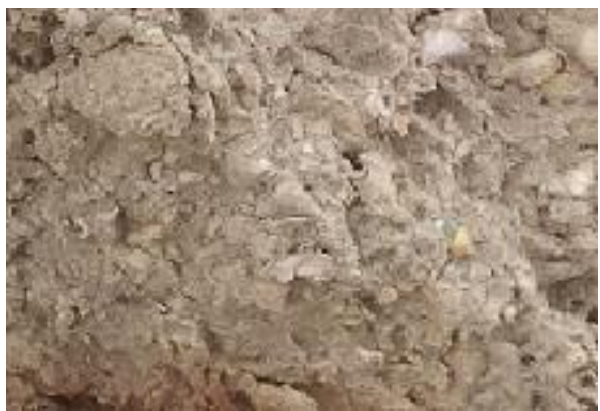

Fig.8 Structure of Papercrete

\section{CONCLUSION}

From this investigation, the following conclusions can be derived on the basis of the tests:

- A Papercrete brick consists of recycled material and therefore cost is low compared to conventional bricks.

- Papercrete can be easily moulded into any shape, bricks are much easier for someone to lift to any desired height and very good surface finish can be achieved.

- Papercrete bricks are suitable for non-load bearing walls only.

- Papercrete has good fire resistance.

- The weight of this brick is almost half the weight of conventional clay brick. Due to less weight of these bricks, the total dead load of the building will be reduced.
- These bricks are potentially ideal material for earthquake prone areas as they are lightweight and flexible.

- $\quad$ These bricks are not suitable for water logging and external walls. It can be used in inner partition walls. This research is just an initiation to papercrete study. However, further studies are required on following issues:

- Modification of mix proportions to achieve optimum properties.

- Addition of materials like coconut fibres or fly ash to improve compressive strength of papercrete.

- Colour and texture for better aesthetics and design versatility.

- Addition of silicon, concrete sealer or epoxy compound to help in waterproofing of papercrete. 
- Admixtures can also be added to improve setting and bonding properties.

- Studies on various other sustainable aspects.

\section{REFERENCES}

[1] G.V.S. Prasad, Study and Behaviour of some Properties of Papercrete Brick with Modular Brick, International Journal of Engineering Research-Online, 3(3), 2015.

[2] K.Anandaraju, B. Jose Ravindra Raaj, R. Vijayasarathy, Experimental Investigation of Papercrete Brick, International Journal of Machine and Construction Engineering, ISSN (Online): 2394-3025, 2(2), June 2015.

[3] Shivangni Khandelwal, Kishan Lal Prajapat, Mukul Kumar, Lohit Bhantia, Ashish Sharma, Vinit Sharma, Review on Papercrete, International Journal of Combined Research \& Development (IJCRD), 4(6), June 2015.

[4] T. Subramani, V. Angappan, Experimental Investigationof using Papercrete, International Journal of Application or
Innovation in Engineering \& Management (IJAIEM), 4(5), May 2015.

[5] M. Scinduja, S. Nathiya, C.V. Shudesamithronn, M. Harshavarthana Balaji, T. Sarathivelan, S. Jaya Pradeep, Innovative Brick Material, International Journal for Research in Applied Science \& Engineering Technology (IJRASET), 1, October 2014.

[6] R.Selvaraj, R. Priyanka, M. Amirthavarshini, Dr. S. Prabhavathy, Evaluation of Papercrete : An Innovative Building Material, International Journal of Engineering \& Advanced Research Technology (IJEART), ISSN: 2454-9290, 1(6), December 2015.

[7] Hemant Sood, Laboratory Manual on Testing of Engineering Materials (New Age International Publisher, Delhi, 1996).

[8] Jil Tushar Seth, Saransh Joshi, Papercrete : A Sustainable Building Material, CEPT University, Ahmedabad, Gujarat, INDIA. 